\title{
Using Online Simulation Technique for Revenue-Based Value for Money Assessment Model in PPP Project
}

\author{
http://dx.doi.org/10.3991/ijoe.v9i3.2804 \\ Wei Peng ${ }^{1,2}$, Honglei Liu ${ }^{1, *}$ \\ 1 Tongji University, Shanghai 200092, China \\ ${ }^{2}$ University of Maryland, College Park, MD, USA
}

\begin{abstract}
Infrastructure public private partnerships (PPP) procurement must be carefully selected on the basis of value for money when compared to conventional procurement. While the value for money analysis has been widely used to ensure low procurement cost in PPP, little is known with respect to its effectiveness and data source. The paper explores existing value for money assessment model and reports its deficiencies in ignoring project revenue and network data collecting. Addressing the current issues, a new revenue based value for money assessment model with Monte Carlo simulation technique is proposed. Data used for simulation come from project participants who obtain and share data through an online virtual collaborative platform. By applying this online technique, project data is more easily shared and reused. This data transmission process is automated and seamless. Then, the effectiveness of new model was examined by using a hypothetical toll road case. It shows that the new value for money assessment model demonstrates the significant advantage in estimating the risk, cost, and revenue variance and assisting the public agency to make decision in the procurement phase.
\end{abstract}

Index Terms-Public Private Partnerships, Value for Money, Simulation, Decision Support.

\section{INTRODUCTION}

Since the use of Public Private Partnerships (PPP) has gained increasing global popularity, countries such as United Kingdom spent approximately $12 \%$ of its total annual infrastructure capital expenditure in PPP. PPP can often be characterized as a contractual agreement where the private entities provide the construction or management of public facilities to the users on behalf of the public agency. In return, the government would compensate the private sectors for the provision of services with project revenue or payments.

The paramount objective of undertaking PPP is achieving improved value for money, or improved services for the same amount of money, as the public sector would spend to deliver a similar project [1]. Since, the public agencies often conduct the Value for Money (VfM) analysis to ensure the VfM result. VfM is often regarded as a monetary value savings produced by selecting the PPP option versus a traditional procurement option. The calculation of such savings is the concept behind the VfM analysis or VfM assessment. If the cost of the traditional procurement is higher than the PPP, the difference between the two costs is the potential savings, or the VfM that can be achieved through the PPP procurement option [2].
However, the current VfM analysis deals only the first phase of ensuring VfM from PPP projects, namely procurement cost. The analysis demonstrates that once the best deal is secured, VfM is assured. Nevertheless, the cost is just one dimension of the VfM objectives. It is also critical to comprehensively consider the impact of project revenue and risk variance and use the online simulation technique to get the accurate data. So attention must be paid to the integration of lifecycle data include cost, revenue and risk from multiple project disciplines.

Given that, our paper tries to present a revenue-based VfM assessment model using online simulation technique. Before delving into the specifics of the simulation model, however, it is first necessary to discuss the typical VfM assessment tool. Thus, the second section of the article provides an overview of existing VfM research. The third section presents typical VfM assessment procedure. Finally, a case study was given, where the online Monte Carlo modeling technique was used in the new model to assess a range of potential cash flow outcomes for the PSC (Public Sector Comparator) and PPP bid.

\section{LITERATURE REVIEW OF VALUE FOR MONEY ASSESSMENT}

The central element of VfM assessment is the standard investment appraisal technique based on the comparison of the discounted cash flows of different options. In the comparison, it aims to select the one that offers the greatest financial benefits, although affordability and public service obligations should also be considered [3]. Adopting appropriate methods to determine value for money for a PPP is not an easy work.

Many researchers found several faults in VfM assessment, including PSC assumption [1], affordability [4], accountability [5], risk [6], unreliability of assessment [1] and quantitative assessment [7], [8]. The major critiques and concerns were summarized to the traditional PSC-PPP VfM tests; say the arbitrariness of the cost comparison. It is suggested that the PSC calculation is merely one factor in the procurement decision. The value for money is more often than not poorly understood and often equated with the lowest cost.

Against the faultiness and deficiencies of the appraisal approach, researchers have also tried to make improvement in NPV calculation [9], robust PSC mechanism [10], usage of Life Cycle Costing [11], the design of evaluation approach [12] and post-evaluation [13]. For example, a method integrating cost-benefit analysis and option pric- 
ing concepts was proposed into urban renewal projects [12]. This model is more appropriate to realizing social benefits and costs yielded to the local residents in the appraisal process.

\section{CurRent VAlue For MONEy ASSESSMEnT Model}

Although the specific workings of VfM assessment may differ between agencies, typically the analysis involves some financial comparison of the net present cost of PPP with that of conventional procurements. There are usually two components to a VfM assessment through the project lifecycle: quantitative and qualitative assessment. In the quantitative assessment, PSC has been developed as a benchmark to test whether a private investment proposals offers value for money in comparison with the public procurement. The PPP bids will be assessed against the PSC shown as Fig. 1, which adapted from [2]. The PSC estimates the hypothetical risk-adjusted costs of public procurement which mainly includes four core elements including the raw PSC, competitive neutrality, transferable risks and retained risks. These elements incurred in the project's delivery are discounted as net present cost terms by using the nominal discount rate. Both probability valuation technique and sensitivity analysis were used to evaluate the risk adjusted PSC and the received PPP bids.

Assessing the private bids against the PSC gives a quantitative answer to the question of value for money. After quantitative assessment, the next step is to qualitatively assess all the factors that cannot be quantified. If $\mathrm{VfM}$ is demonstrated in the quantitative process, then a public agency can set up to pursue the project as a PPP (assuming the project also passed the qualitative test). If VfM is not demonstrated, then alternative procurement routes would be considered.

\section{REVENUE-BASED VALUE FOR MONEY ASSESSMENT MODEL}

Generally, toll revenues and other project-based revenues reduce the net financial impact to the public agency in pursuing the project through a conventional procurement or PPP procurement. The present value of these revenues is therefore should be deducted from the total present value of the PSC to get the NPV for PSC or PPP bid. However, the current VfM assessment model does not have this step. Thus, we propose a new model of comparing the PSC to the PPP alternative which incorporating the project revenues in PSC and PPP bids, shown as in Fig. 2. The data source used in the model comes from the virtual collaborative platform by online way. These data mainly include project cost, risk profile, revenue information provided by stakeholders, such as public sector, private sector, operator and contractor. The virtual collaborative platform provided project data resource forming a reliable information basis during the whole project life-cycle from the early conception stage to the final demolition [14]. This platform maintains a single, non-redundant repository of project data, and allows native applications to import and export files from the database for viewing, checking, updating and modifying procedure [15]. The overall system is automated and seamless, shown as Fig. 3. Since the platform produced the reliable data source, online Monte Carlo simulation is then developed within three steps (preprocessing-Simulation-Post-processing), as shown in Figure 4, which illustrates the general uncertainty/ sensitivity analysis procedure. These steps of online-based uncertain-

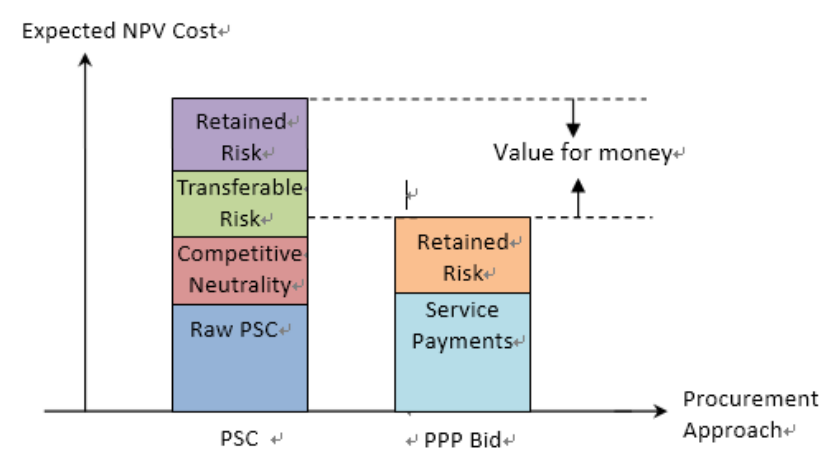

Figure 1. VfM Comparison of PSC and PPP bids

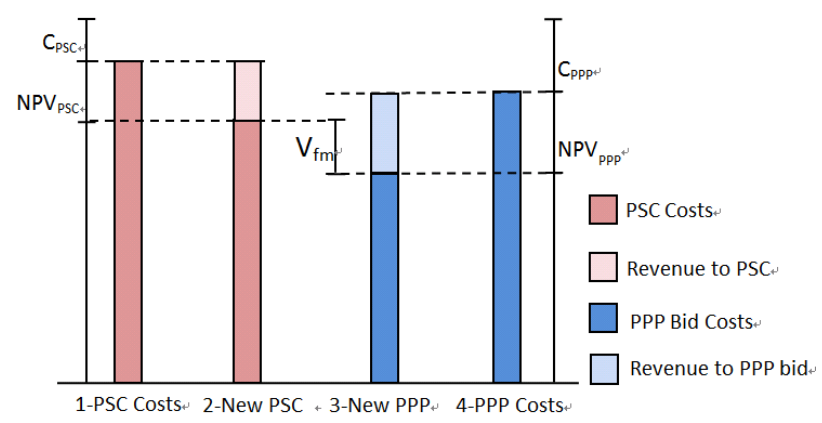

Figure 2. Revenue-based VfM comparison model

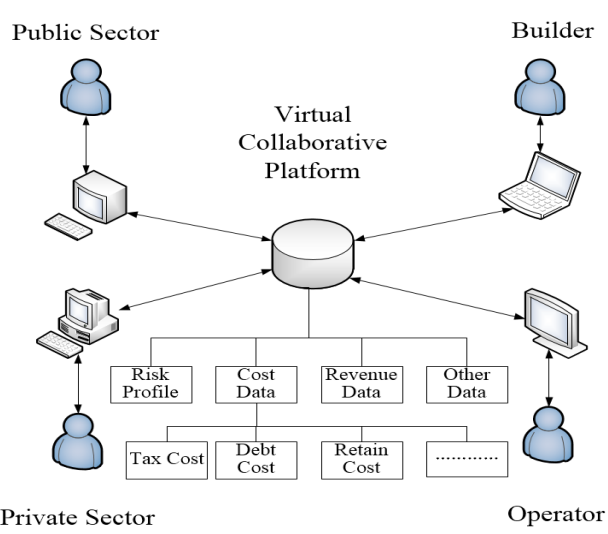

Figure 3. Data acquisition mode and source

ty analysis proceeds as follows: (1) selection of input variables plausible ranges and simulation scenario from virtual platform, (2) sampling of unknown variables performed by toolkit, and (3) self-activating uncertainty and sensitivity analysis. The results are saved in the folder of the project executive file.

After we get the sampling simulation result, the final outcome of value for money assessment is depending on the difference of NPV between traditional and publicprivate routes (the bar 2 and bar 3 in Fig. 2.) which can be calculated as follows.

$$
\begin{gathered}
\mathrm{NPV}_{P S C}=\sum_{i=1}^{m} \frac{C_{i 1}-R_{i 1}}{(1+r)^{i}}+\sum_{j=1}^{n} r_{j 1} \\
\mathrm{NPV}_{\mathrm{PPP}}=\sum_{\mathrm{i}=1}^{\mathrm{m}} \frac{\mathrm{C}_{\mathrm{i} 2}-\mathrm{R}_{\mathrm{i} 2}}{(1+\mathrm{r})^{\mathrm{i}}}+\sum_{\mathrm{j}=1}^{\mathrm{n}} \mathrm{r}_{\mathrm{j} 2} \\
\mathbf{V}_{f m}=\mathrm{NPV}_{P S C}-\mathrm{NPV}_{P P P}
\end{gathered}
$$

The degree of value for money $V_{f m}$ is represented by the deviation of net present value of tow procurement 


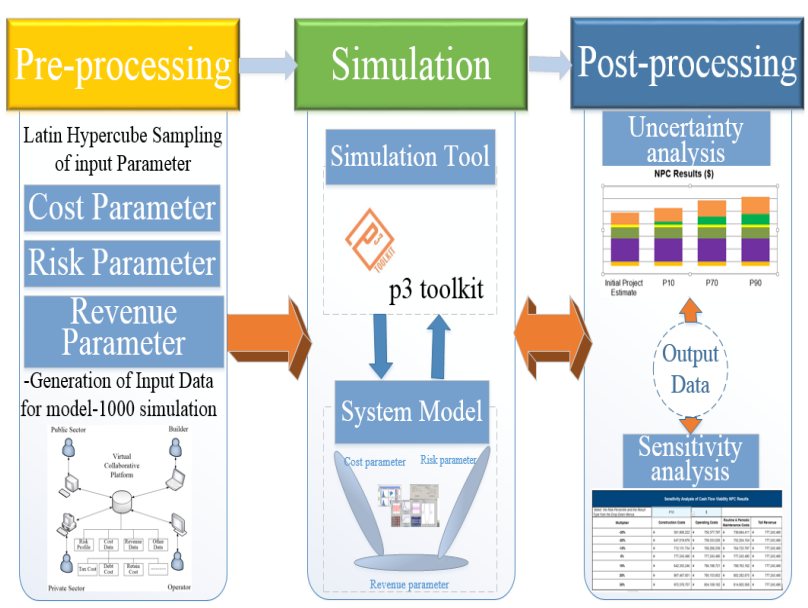

Figure 4. Online based Monte Carlo simulation

routes. Where, $\mathrm{C}_{\mathrm{i}}$ is the sum of costs including design, construction, operation, maintenance, financing and other project costs incurred by the entity in the $i_{\text {th }}$ year. $R_{i}$ is the project revenue item. And $r_{j}$ represent the retained and transferred risk value. The index i1, j1 and i2, $\mathrm{j} 2$ denote the corresponding indexes of PSC and PPP bid respectively. And $r$ is the discount rate in calculating the present values of the costs and revenue.
In the following part, an example used the revenue based quantitative VfM analysis for a hypothetical highway project is presented. This model compares the NPV of cash flows under a traditional procurement PSC to PPP alternatives. The first step in performing a value for money analysis should be to conduct the risk assessment. Therefore, we use the Monte Carlo simulation technique to quantify risks in terms of both cost and time impact with a value of 1,000 simulated runs. A Monte Carlo simulation produces a deterministic sample set of likely risk outcomes and the probabilities of their occurrence [16]. The sample set is then used to develop distributions and ranges for aggregate cost and schedule impacts. The main output of the simulation is total values for retained and transferred risks, for both the PSC as well as for the PPP Bid. Based on the data support from virtual collaborative platform, the P3 tool kit developed by the Federal Highway Administration (FHWA) was selected as the simulation tool to generate several types of simulation charts. Fig. 5 and 6 show examples of probability frequency distributions of aggregated cost and schedule risk impact.

The simulation provides a range of aggregate risk values that the agency may choose from, depending on what confidence threshold is required. In Table I, the 10 th percentile (also known as the P10), 50th percentile (P50) and

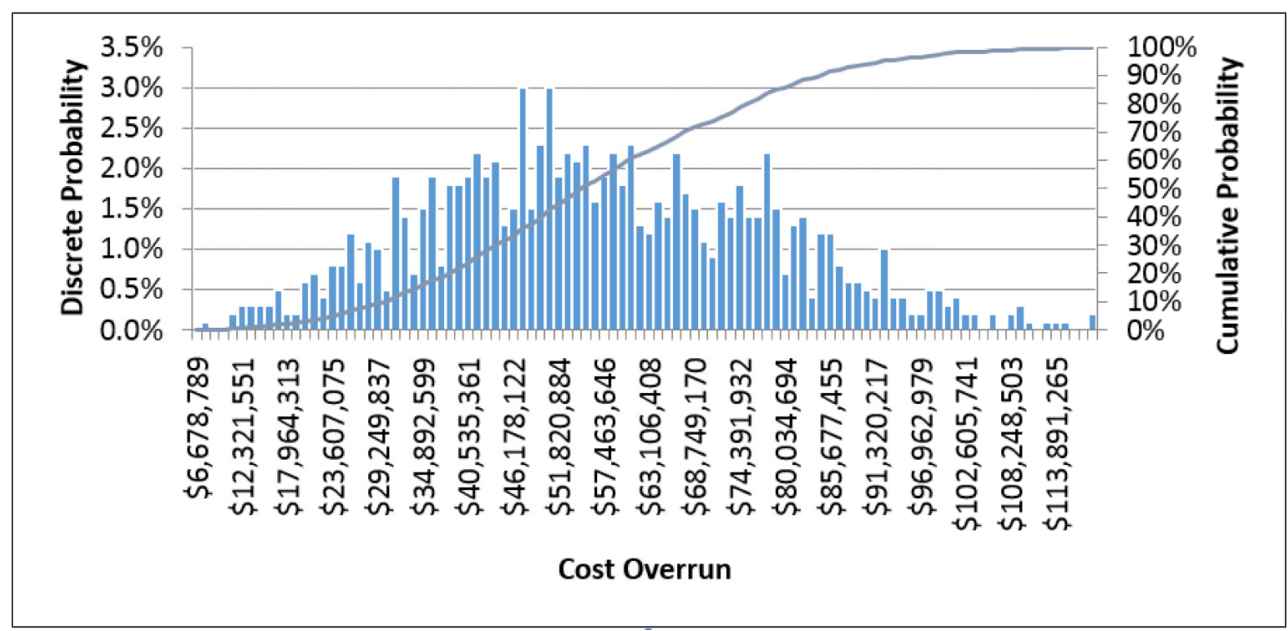

Figure 5. Cost overrun estimates

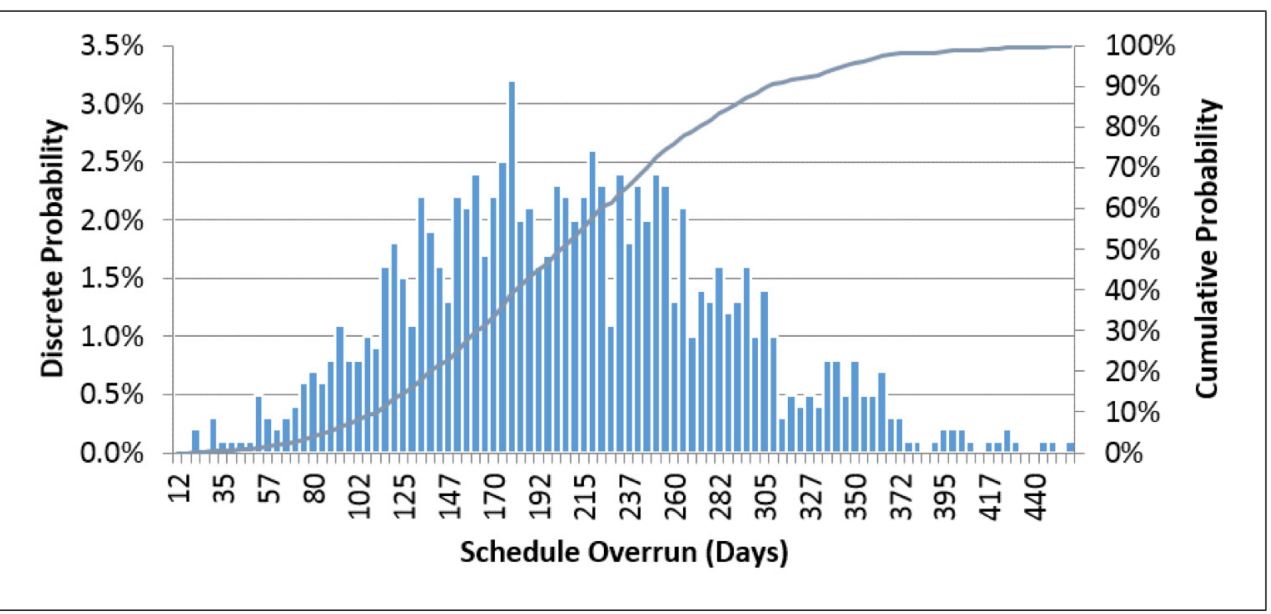

Figure 6. Schedule overrun estimates 
Using Online Simulation TechniQue for ReVEnUE-BASEd VAlue For Money AsSessment Model IN...

90th percentile (P90) are shown since these are the most commonly reported risk statistics. A private bidder may choose to use a lower P-level to 50 estimate risk costs, choosing to be compensated through a higher required rate of return on equity contributions.

The simulation provides a range of aggregate risk values that the agency may choose from, depending on what confidence threshold is required. In Table I, the 10 th percentile (also known as the P10), 50th percentile (P50) and 90th percentile (P90) are shown since these are the most commonly reported risk statistics. A private bidder may choose to use a lower P-level to 50 estimate risk costs, choosing to be compensated through a higher required rate of return on equity contributions.

Fig. 7 and Fig. 8 provide the simulated PSC and PPP bid cash flow summary charts indicating the total costs and revenues of the public or private delivery over the 40 years of project life. The first chart may be useful in understanding how the project's cash flows under public sector delivery impact the agency's budget. And the second chart is also helpful as it considers the budgetary impact of delivering the project as PPP. Using the Eq.1 and 2 the net present value associated with the PSC and the P3 can be obtained for comparative purposes. Particularly, the revenues in the PSC and PPP bid are \$ $5,828,794$ and $\$ 873,189,169$, respectively. The net pres-
TABLE I.

COST AND SCHEDULE RISK RESULTS

\begin{tabular}{|c|c|c|c|}
\hline $\begin{array}{c}\text { Cost Risk } \\
\text { Results }\end{array}$ & Real Dollars & $\begin{array}{c}\text { Schedule Risk } \\
\text { Results }\end{array}$ & Days Delay \\
\hline $\begin{array}{c}\text { P10 Im- } \\
\text { pact }\end{array}$ & $\$ 29,856,295$ & P10 Impact & 112 \\
\hline $\begin{array}{c}\text { P50 Im- } \\
\text { pact }\end{array}$ & $\$ 54,561,206$ & P50 Impact & 204 \\
\hline $\begin{array}{c}\text { P90 Im- } \\
\text { pact }\end{array}$ & $\$ 84,373,579$ & P90 Impact & 306 \\
\hline
\end{tabular}

ent value NPVpsc is $\$ 1,392,869,866$, while the NPVppp is $\$ 1,051,586,891$. Thus the notional value for money

$\mathrm{V}_{\mathrm{fm}}$ is $\$ 341,282,975$ which is around $25 \%$ of PSC value.In this scenario, it is reasonable to choose the PPP as the preferred delivery method. However if we do not consider the revenue impact in the assessment process just as the traditional VfM method, the consequence is totally different. The total payment for the PPP bid is approximately 1.8 billion dollars which is larger than the 1.3 billion of public procurement cost. According to the traditional value for money analysis, the PPP procurement method is not a good choice in this case. The result provided in this case reflect the importance and effectiveness of new VfM assessment model in assisting governments to make the right decision.

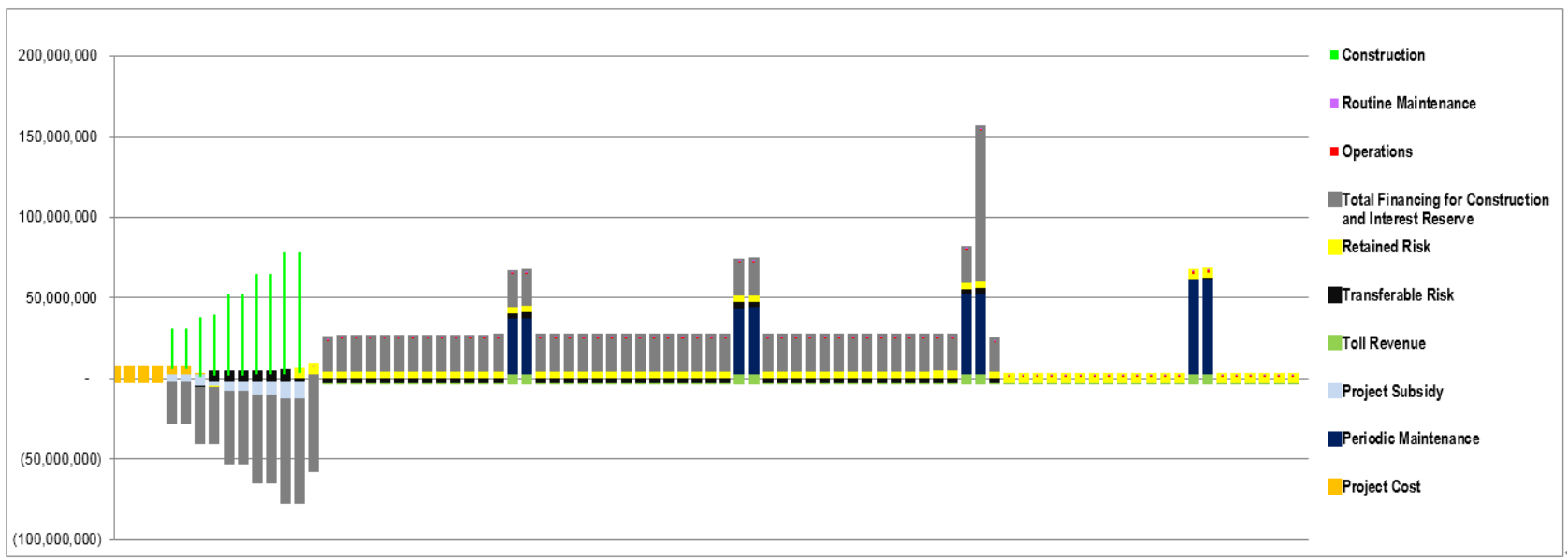

Figure 7. Simulated PSC cash flow summary

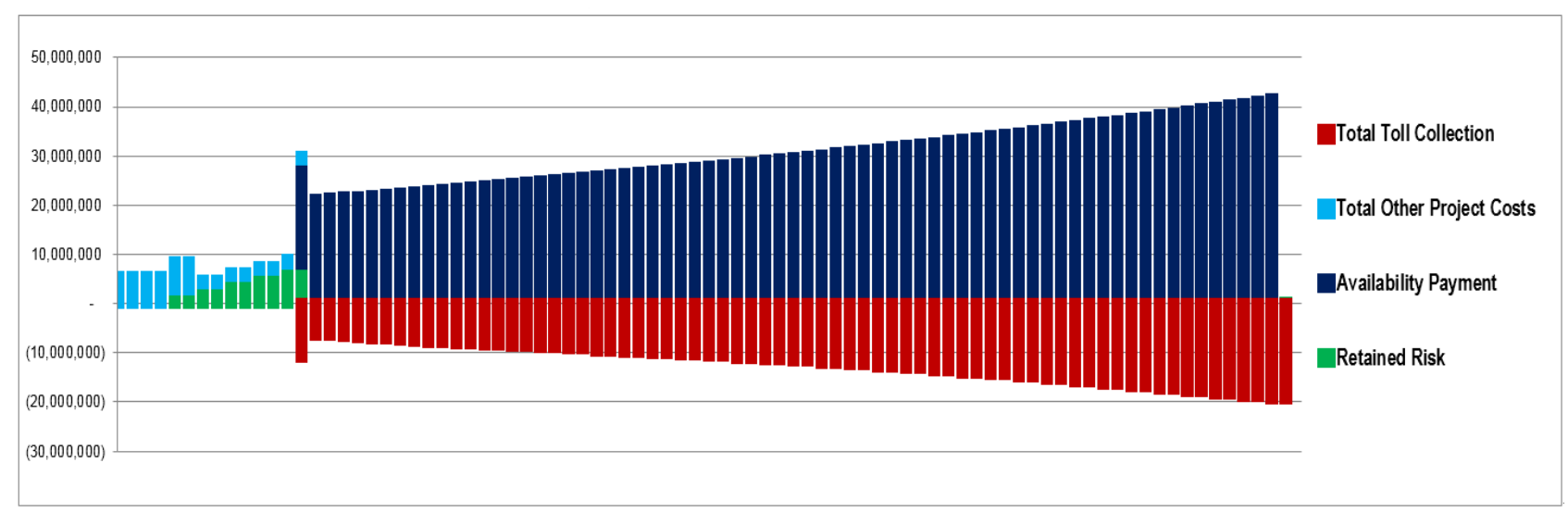

Figure 8. Simulated PPP bid cash flow summary 


\section{CONCLUSION}

With respect to VfM, it is founded that although the standardized official definition is ensuring the best mix of quality and effectiveness, the evaluation is often based on a comparison of cost between alternative procurement routes. This evaluation has shortfall in its preoccupation with cost control rather than value delivery or impact of revenue. The current assessment framework requires modifications to analyze the projects where the project is expected to be financed through private funds. Thus, this paper suggests necessary revisions for current appraisal and consideration for the differences in the ability of the private and public sectors to maximize toll revenue yield over the term of the agreement. In which, online technique is applied to obtain more accurate, reliable and comprehensive cost and revenue data. This online way is transparent and automated. The results, partly shows the viability and effectiveness of revenue based VfM assessment system. More examinations and refinements of this model are required in the future study.

\section{ACKNOWLEDGMENT}

\section{REFERENCES}

[1] Grimsey D, Lewis M K. "Are Public Private Partnerships value for money? Evaluating alternative approaches and comparing academic and practitioner views," Accounting Forum, 29(4), (2005), pp.345-378. http://dx.doi.org/10.1016/j.accfor.2005.01.0 01

[2] Morallos D, Amekudzi A. "The state of the practice of value for money analysis in comparing public private partnerships to traditional procurements," Public Works Management \& Policy, 13 (2008), pp.114-125. http://dx.doi.org/10.1177/1087724X08326 176

[3] Shaoul J. "A critical financial analysis of the Private Finance Initiative: selecting a financing method or allocating economic wealth?" Critical Perspectives on Accounting, 16 (2005), pp.441-471.http://dx.doi.org/10. 1016/j.cpa.2007.05.001

[4] Froud J, Shaoul J. "Appraising and evaluating PFI for NHS hospitals," Financial Accountability \& Management, 17 (2001), pp.247-270. http://dx.doi.org/10.1111/1468-0408.00130

[5] Khadaroo I. "The actual evaluation of school PFI bids for value for money in the UK public sector," Critical Perspectives on Accounting, 19 (2008), pp.1321-1345. http://dx.doi.org/10.1016/j. cpa.2007.05.001

[6] Heald D. "Value for money tests and accounting treatment in PFI schemes". Accounting, Auditing \& Accountability Journal, 16 (2003), pp.342-371. http://dx.doi.org/10.1108/09513570310 $\underline{482291}$

[7] Coulson A. "Value for money in PFI proposals: a commentary on the UK treasury guidelines for public sector comparators," Public Administration, 86 (2008): pp. 483-

498.http://dx.doi.org/10.1111/j.1467-9299.2008.00729.x
[8] Akintoye A, Hardcastle C, Beck M, et al. "Achieving best value in private finance initiative project procurement." Construction Management and Economics, 21 (2003), pp.461-470.http://dx. doi.org/10.1080/0144619032000087285

[9] Chiang Y H, Cheng E W L, Lam P T I. "Employing the net present value-consistent IRR methods for PFI contracts," Journal of Construction Engineering and Management, 136 (2010), pp.811-814. http://dx.doi.org/10.1061/(ASCE)CO.19437862.000 $\underline{0179}$

[10] Lamb D, Merna A. "Development and maintenance of a robust public sector comparator," The Journal of Structured and Project Finance, 10 (2004), pp. 86-95.

[11] Olubodun F, Kangwa J, Oladapo A, et al. "An appraisal of the level of application of life cycle costing within the construction industry in the UK," Structural Survey, 28 (2010), pp.254-265.

[12] Leung B Y P, Hui E C M. "Evaluation approach on publicprivate partnership (PPP) urban redevelopments," International Journal of Strategic Property Management, 9 (2005), pp.1-16. http://search.ebscohost.com/login.aspx?direct=true \&db=bth\&A $\mathrm{N}=16872721 \&$ site $=$ ehost-live

[13] English L M, Guthrie J, Broadbent J, et al. "Performance Audit of the Operational Stage of Long-Term Partnerships for the Private Sector Provision of Public Services," Australian Accounting Review, 20 (2010), pp.64-75. http://dx.doi.org/10.1111/j.18352561.2010.00075.X

[14] Xiaolong Xue, Qiping Shen, et al. "IT supported collaborative work in A/E/C projects: A ten-year review," Automation in Construction, 21 (2012), pp. 1-9. http://dx.doi.org/10.1016/j.autcon. 2011.05.016

[15] Vishal Singh, Ning Gu, Xiangyu Wang. "A theoretical framework of a BIM-based multi-disciplinary collaboration platform," Automation in Construction, 20 (2011), pp. 134-144. http://dx.doi.org/10.1016/j.autcon.2010.09.011

[16] Decorla-Souza P, Lee D, Timothy D, et al. "Comparing PublicPrivate Partnerships with Traditional Procurement: Incorporating Considerations from Benefit-Cost Analysis," Transportation Research Board 92nd Annual Meeting, (2013), pp.1-13.

\section{AUTHORS}

*Honglei Liu: (*Corresponding Author) is the $\mathrm{PhD}$ student of School of Economics and Management, Tongji University, Shanghai 200092, China (Email: 666honglei@gmail.com).

Wei Peng is the PhD student of School of Economics and Management, Tongji University, Shanghai 200092, China.

This article is an extended and modified version of a paper presented at the International Conference on Mechanical Engineering, Automation and Material Science (MEAMS2012), held 22-23 December 2012, Wuhan, China. This research was supported by a Grant from the Shanghai Science and Technology Council, the Fundamental Research Funds for the Central Universities and the Shanghai Leading Academic Discipline Project (No.B310). Received 19 May 2013. Published as resubmitted by the authors 12 June 2013. 